Revista Destaques Acadêmicos, Lajeado, v. 11, n. 4, 2019. ISSN 2176-3070

DOI: http://dx.doi.org/10.22410/issn.2176-3070.v11i4a2019.2402

http://www.univates.br/revistas

\title{
AVALIANDO A TÉCNICA DE APRENDIZADO POR REFORÇO NEAT QUANDO APLICADA A UMA REDE NEURAL JOGANDO UM VIDEOGAME DE CONSOLE DE 8 BITS
}

\author{
Alan Soder ${ }^{1}$, Marcelo de Gomensoro Malheiros ${ }^{2}$
}

\begin{abstract}
Resumo: Junto à recente popularidade da Inteligência Artificial, amparada na redução dos custos de hardware massivamente paralelo, surgiu um crescente interesse em algoritmos de autoaprendizado. Em outras palavras, em processos que permitam a uma rede neural aprender de forma não supervisionada. Quando o ambiente para aprendizado é dinâmico, podem ser aplicadas técnicas de Aprendizado por Reforço, que permitem que uma rede neural seja refinada por sucessivas tentativas. Em particular, ambientes simulados como os providos por jogos de computador são ideais para aplicar este aprendizado, tanto pelo desafio técnico como pelo seu fator lúdico. Este artigo descreve um estudo sobre a aplicação do algoritmo NEAT para treinar automaticamente uma rede neural para jogar o clássico videogame de ação Gradius, lançado para o console de 8 bits Nintendo Entertainment System (NES). O algoritmo NEAT é especialmente interessante, pois aplica técnicas de algoritmos genéticos para evoluir a topologia de uma rede neural, modificando também os pesos das suas conexões. Este trabalho fundamenta as questões técnicas envolvidas, apresentando os resultados da ligação entre uma rede neural que se inicia com zero conhecimento e um emulador capaz de executar o jogo eletrônico. São analisados os diversos efeitos dos parâmetros de aprendizado e dos ajustes feitos na função de fitness. Ao final, é demonstrado que a rede neural artificial se torna capaz de jogar autonomamente um trecho inicial daquele jogo.
\end{abstract}

Palavras-chave: Inteligência Artificial. Aprendizado de Máquina. Aprendizado por Reforço. NEAT. Jogos Eletrônicos.

1 Graduado em Engenharia da Computação pela Universidade do Vale do Taquari - UNIVATES. alanbr4@gmail.com

2 Professor na Universidade do Vale do Taquari - UNIVATES. Doutor em Computação na UFRGS - RS, mestre em Engenharia Elétrica na UNICAMP - SP, graduado em Engenharia da Computação na UNICAMP - SP. mgm@univates.br 


\section{INTRODUÇÃO}

A Inteligência Artificial (IA) é considerada um dos campos mais novos da Ciência, tendo início após a Segunda Guerra Mundial. Seu principal foco tem sido reproduzir o processo de pensamento humano em máquinas, sendo movida por questionamentos do tipo "como é possível que uma porção de carne possa perceber, entender e manipular coisas muito maiores e mais complicadas que si próprio" (RUSSEL; NORVIG, 2010).

De acordo com Hoojat (2015), a evolução da velocidade, disponibilidade e escala reduzida das infraestruturas, com a redução do custo das GPUs (Graphics Processing Units), permitiram que a IA se tornasse um dos assuntos mais populares da atualidade. Diversas técnicas que geralmente eram feitas em laboratórios especializados, agora podem ser realizadas no computador de uma pessoa comum. Esta nova realidade democratizou o acesso a um mundo antes restrito a poucos.

Ainda que a área da Inteligência Artificial esteja em evidência, os avanços mais impressionantes dos últimos anos estão ligados a Redes Neurais Artificiais (RNA) e a resultados expressivos de precisão no reconhecimento de padrões, muitas vezes ultrapassando humanos em tarefas como tradução de texto, identificação de imagens ou análises não-triviais de indicadores biológicos. A sub-área da IA que se dedica ao treinamento e avaliação de redes neurais é chamada de Aprendizado de Máquina.

Este trabalho pretende estudar e avaliar um caso particular de treinamento de rede neural, quando não há intervenção humana e quando os dados para aprendizado provêm de um processo de retroalimentação automatizado. Nesse caso, estamos falando do treinamento conhecido como Aprendizado por Reforço (Reinforcement Learning, em inglês).

Foi selecionado como objeto de estudo o algoritmo genético NeuroEvolution of Augmenting Topologies (NEAT), que emprega técnicas de modificação evolutiva para maximizar os resultados da aprendizagem. Como ambiente de simulação para prover as medidas de treinamento, escolheu-se o jogo Gradius, título clássico do console de videogame de 8 bits Nintendo Entertainment System (NES).

Este artigo descreve como um jogo pode ser controlado por uma rede neural artificial, funcionando dentro de um software emulador especializado. Os objetivos específicos deste trabalho são: estudar os principais conceitos de aprendizado por reforço, mapear soluções de software pré-existentes para a montagem do sistema de aprendizado, aplicar o algoritmo NEAT ligado a um emulador de console NES e finalmente avaliar os resultados obtidos. 


\section{REFERENCIAL TEÓRICO}

Esta seção define brevemente os conceitos principais utilizados neste trabalho, assim como dá uma visão geral sobre o funcionamento do algoritmo NEAT.

\subsection{Aprendizado de Máquina}

Aprendizado de Máquina (AM) é um método que visa automatizar a criação de modelos analíticos. É uma das linhas da Inteligência Artificial que se apoia na ideia de sistemas de aprendizado automáticos através de dados, identificação de padrões e tomadas de decisões sem ou quase sem interferência humana (SAS, 2018).

Nas últimas três décadas, Aprendizado de Máquina se tornou uma das principais áreas de tecnologia, muitas vezes sem ser percebida. Um dos motivos disto é o grande aumento das bases de dados categorizados que estão disponíveis.

O Aprendizado de Máquina pode ser usados para diversos fins, sendo que os mais conhecidos são os de motores de buscas, como o utilizado pelo Google para aprimorar pesquisas; filtragem colaborativa (collaborative filtering) da Amazon e Netflix que realizam indicações de produtos e filmes, além da tradução automática, técnica utilizada pelo parlamento do Canadá (SMOLA; VISHWANATHAN, 2008).

\subsection{Redes Neurais Artificiais}

Uma Rede Neural Artificial (RNA) é um sistema paralelo e distribuído, composto de unidades de processamento triviais (neurônios artificiais) alocados em uma ou diversas camadas interconectadas por um grande número de conexões com o objetivo de calcular funções matemáticas. Estas ligações normalmente estão integradas a pesos, esses utilizados para armazenar o conhecimento e avaliar todas as entradas de cada neurônio.

As RNAs são atrativas devido ao seu poder de aprendizagem através de exemplos e da generalização da informação obtida. A generalização está ligada à aptidão da rede em aprender por intermédio de um conjunto de amostras e, em seguida, apresentar respostas para informações não apresentadas anteriormente. Além disso, outra propriedade que faz das RNAs importantes é a eficácia de se auto-organizar e a possibilidade de processamento temporal (BRAGA et al., 2011).

\subsection{Aprendizado por Reforço}

Aprendizado por Reforço (AR) é, simultaneamente, um problema, a solução para resolução de problemas e a área de estudo que pesquisa deste assunto. Problemas de AR envolvem descobrir como estruturar ocorrências em 
ações e, também, como maximizar a indicação de recompensa. Essencialmente, esses problemas necessitam ser repetitivos, pois o sistema de aprendizado é influenciado pelos resultados das ocorrências anteriores.

Diferente das formas normais de Aprendizado de Máquina, AR não especifica quais ações adotar e sim as que deram melhores resultados após a tentativa. Além disto, todas as ações tomadas por uma rede neural de AR refletem em futuros eventos (SUTTON; BARTO, 2016).

\subsection{Algoritmo Genético}

Um Algoritmo Genético (AG) tem como o objetivo a otimização e a busca da melhor solução para uma vasta série de problemas. Seu funcionamento simula o processo de evolução natural, que permitiu o surgimento de uma grande variedade de seres vivos. O ponto fundamental é avaliar a capacidade de uma certa espécie em se adequar ao seu ambiente (KRAMER, 2017).

Os AGs são também inspirados em conceitos da genética, utilizando para isso diversos componentes e processos. Os principais são a codificação do cromossomo, a função de aptidão, o processo de seleção, a etapa de recombinação e o esquema de evolução.

Algoritmos Genéticos manipulam populações de cromossomos que são representações em formato de texto de soluções para problemas. Um cromossomo é uma abstração de um DNA biológico, que pode ser representado por um conjunto de letras do alfabeto. A função de aptidão (em inglês, fitness) é utilizada para medir a qualidade de um cromossomo como solução para um problema específico.

Algoritmos Genéticos utilizam a aptidão como um medidor de qualidade apresentado pelos cromossomos em uma população, guiando a evolução de um cromossomo. Desta forma, cromossomos são selecionados para recombinação baseados em sua aptidão e aqueles com maior aptidão têm maior chance de serem escolhidos, fazendo com que os mais aptos sejam mantidos em gerações futuras.

Recombinação é o processo no qual cromossomos são selecionados em uma população e combinados para formar as próximas populações. Neste processo, há a garantia de que os cromossomos mais aptos sejam evoluídos devido à seleção ter a maior probabilidade de buscar os melhores. Na recombinação há dois processos principais: o cruzamento e a mutação. Estes processos não são exatos e cada um tem uma chance probabilística de acontecer.

Após a recombinação, os cromossomos resultantes passam a fazer parte da população posterior, e o processo de seleção e recombinação são repetidos até que se complete uma nova geração de população. Desta forma, o AG é continuado até que a melhor aptidão (objetivo) seja alcançado ou até que um máximo de gerações (pré-especificadas) seja gerada (MCCALL, 2005). 


\subsection{NEAT}

NeuroEvolution of Augmenting Topologies (NEAT) é um algoritmo genético que visa tirar vantagem de uma rede através de sua estrutura, visando diminuir o tamanho da pesquisa dos pesos das conexões de uma rede neural. Caso a estrutura evolua para que a topologia da rede seja minimizada, e cresça ao longo do tempo, ganhos significativos em velocidade são apresentados.

NEAT é designado para que possam ser colocados em ordem quando há cruzamento. Genomas são representações de conectividade da rede. Cada genoma possui uma lista de genes de conexão, cada um referenciando a dois genes de nó conectados. Genes de nó fornecem uma lista de entradas, contendo nós escondidos, e de saídas que podem ser conectadas. Cada gene de conexão possui um nó de entrada, um nó de saída, seus respectivos pesos, a habilidade de estar ou não ativado e um número de inovação, que permite encontrar os genes correspondentes.

Em NEAT, a mutação pode ocorrer de duas formas: alterando pesos das conexões ou da estrutura da rede. A mutação dos pesos ocorre da mesma forma que em algoritmos genéticos (cruzamento e recombinação). Já a mutação da rede ocorre de duas formas, na qual ambas incrementam os genes: adicionando uma nova conexão ou um novo nó. Os genomas irão gradativamente aumentar por meio destas mutações. Genomas de tamanhos diferentes serão produzidos, às vezes, com conexões diferentes nas mesmas posições (STANLEY; MIIKKULAINEN, 2002).

\section{DESENVOLVIMENTO}

Foi desenvolvido um sistema para avaliação do algoritmo NEAT aplicado ao jogo eletrônico Gradius do Nintendo Entertainment System. Isso foi feito através de scripts escritos nas linguagens Lua e Python, utilizando emulação através do emulador FCEUX.

O sistema operou e foi avaliado em um computador pessoal do tipo desktop, contendo um processador Core I7-4790 com 4,0 GHz com quatro núcleos de processamento, 8 GB de memória RAM, um SSD Kingston de 120GB com velocidades de leitura de $550 \mathrm{MB} / \mathrm{s}$ e escrita $500 \mathrm{MB} / \mathrm{s}$. O sistema operacional utilizado foi o Ubuntu versão 16.04.

A execução do jogo Gradius foi feita pelo emulador FCEUX. Informações importantes sobre o estado do jogo foram extraídas diretamente da memória do sistema emulado, incluindo quantidade de vidas do jogo, se o jogador está vivo ou não, posição vertical e horizontal da nave do jogador, dados sobre os inimigos e pontuação. 


\subsection{Implementação}

O desenvolvimento deste trabalho foi realizado com as linguagens Python e Lua, realizando comunicação entre essas linguagens através da técnica de inter process communication (IPC) utilizando named pipes.

A execução do jogo Gradius no computador ocorreu através do emulador FCEUX versão 2.2.2. FCEUX é um emulador capaz de reproduzir os consoles NES, Famicom Disk System (FDS) e Dendy. Este emulador suporta os formatos de vídeo NTSC (EUA/Japão), PAL (Europa) e NTSC-PAL híbrido. Além disso, reconhece scripts em linguagem Lua. O interpretador de Lua permite realizar operações com as memórias RAM e VRAM, como também executar de forma programada ações que normalmente seriam realizadas pelo controle conectado ao console.

Gradius é um jogo do estilo shoot'em up de deslocamento horizontal e foi desenvolvido pela Konami em 1985 para o NES. Neste jogo o jogador pilota uma nave conhecida como Vic Viper que deve se defender de naves alienígenas. Neste jogo pode-se movimentar, disparar projéteis, pegar e utilizar os bônus que são deixados pelos inimigos quando morrem. Para facilitar o desenvolvimento e aprendizado da rede neural, os bônus não foram utilizados neste trabalho.

\subsubsection{Script Lua}

Todas as interações entre o emulador e o jogo Gradius foram realizadas através de um script Lua, desenvolvido para utilizar as funções disponibilizadas pelo emulador. Através deste script é possível obter as informações necessárias para treinamento da rede com base no conteúdo das memórias RAM e VRAM do console, realizar comandos para movimentar a nave e ainda identificar o que é mostrado na tela (no caso deste trabalho, as informações sobre os inimigos). As informações obtidas da memória do emulador estão no Quadro 1.

Quadro 1: Informações extraídas com o script Lua.

\begin{tabular}{|l|l|}
\hline Informação & Posição da memória/função \\
\hline quadro atual & emu.framecount() \\
\hline posição X VIC & 0x07B7 \\
\hline posição Y VIC & 0x07C7 \\
\hline se a nave está viva ou morta & 0x0100 \\
\hline número de identificação inimigos & 0x0307 - 0x0320 \\
\hline posições X dos inimigos & 0x0367 - 0x0380 \\
\hline posições Y dos inimigos & 0x0327 - 0x0340 \\
\hline
\end{tabular}

Fonte: Elaborado pelos autores (2019). 
Todas essas informações são obtidas através do script Lua funcionando dentro do próprio emulador. Para a realização deste trabalho, os comandos do emulador utilizados estão listados no Quadro 2.

Quadro 2: Lista de comandos utilizados.

\begin{tabular}{|l|l|}
\hline Comando & Descrição \\
\hline emu.frameadvance) & $\begin{array}{l}\text { Avança um quadro do jogo. Ocorre a cada rodada de } \\
\text { envio de entradas para rede neural e retorno das suas } \\
\text { saídas. }\end{array}$ \\
\hline $\begin{array}{l}\text { joypad.set(int player, table } \\
\text { input) }\end{array}$ & $\begin{array}{l}\text { Designa quais serão utilizados pelo jogador } \\
\text { selecionado. Neste trabalho, as saídas da rede neural } \\
\text { foram passadas para esta função. Desta forma pode- } \\
\text { se mover a nave e atirar. Também foi utilizado para } \\
\text { passar os menus do jogo, colocando como comando o } \\
\text { botão start. Exemplo de entrada: }\{0,0,0,0,0,0,1,0\} \text { onde 1 } \\
\text { significa pressionado e 0 não pressionado. }\end{array}$ \\
\hline $\begin{array}{l}\text { memory.readbyte(int } \\
\text { address) }\end{array}$ & $\begin{array}{l}\text { Comando utilizado para leitura dos dados da memória } \\
\text { RAM e VRAM. Todas as entradas da rede neural foram } \\
\text { obtidas através deste comando, selecionando a posição } \\
\text { do dado necessário. }\end{array}$ \\
\hline $\begin{array}{l}\text { emu.speedmode(string } \\
\text { mode) }\end{array}$ & $\begin{array}{l}\text { Com este comando foi possível selecionar o modo } \\
\text { maximum para ter uma velocidade acima da normal } \\
\text { (3200\%). Isso foi essencial no treinamento da rede, pois } \\
\text { foi possível treiná-la muito mais rápido. }\end{array}$ \\
\hline
\end{tabular}

Fonte: Elaborado pelos autores (2019).

Em Lua também há comandos para leitura e escrita de arquivos, necessários para comunicação entre os scripts Lua e Python. Os comandos para leitura e escrita dos pipes foram io.open(path, mode) para abrir o arquivo e arquivo:read() para leitura. Para escrita, os comandos utilizados foram arquivo:write(string data), arquivo:flush() e arquivo:close(). Um exemplo de código para escrita de arquivo (neste caso o pipe) é o ilustrado no Quadro 3. 
Quadro 3: Exemplo de função escrita em Lua.

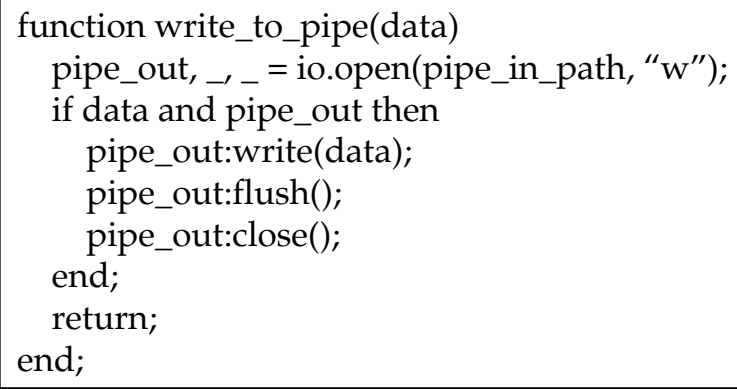

Fonte: Elaborado pelos autores (2019).

\subsubsection{Comunicação}

A comunicação entre o script de Python e o script de Lua é realizada através de IPC, utilizando named pipes. Named pipes são dispositivos de comunicação unidirecional que permitem escrita de bytes em um processo e a leitura em outro (RITCHIE; THOMPSON, 1974). O esquema de comunicação utilizado no trabalho pode ser visto na Figura 1. Como em um pipe há apenas um caminho de comunicação, há necessidade de dois para haver ida e volta de informação.

Figura 1: Esquema de comunicação entre as duas linguagens.

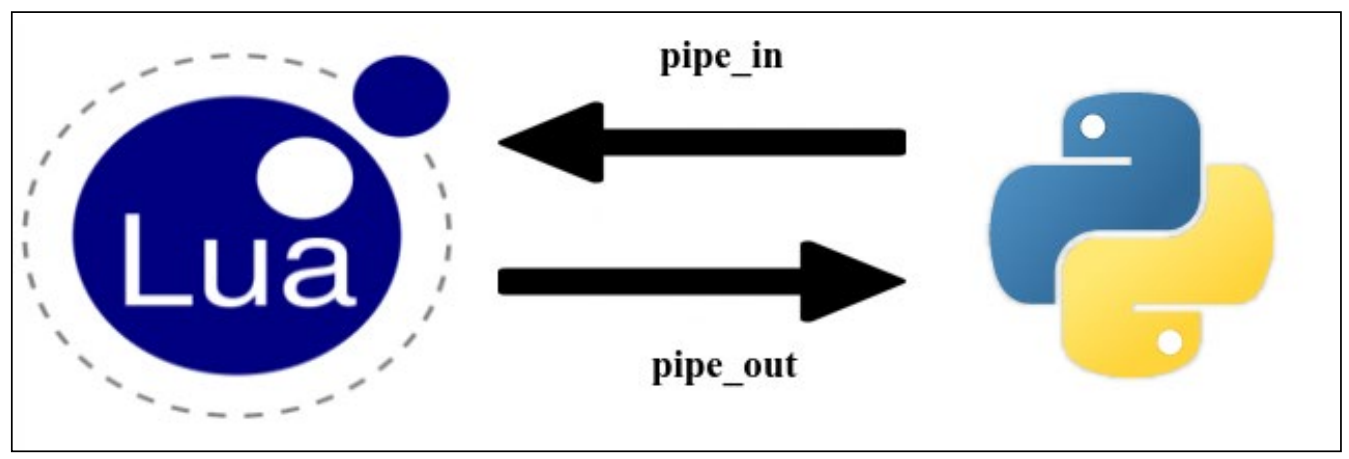

Fonte: Elaborado pelos autores (2019).

\subsubsection{Script Python}

O desenvolvimento em Python visou a criação da inteligência deste trabalho. Foi desenvolvida a integração com o módulo NEAT-Python para treinamento da rede neural com os dados recebidos através do pipe processados com o script Lua. 
$\mathrm{O}$ uso da linguagem Python foi essencial, pois esta possui diversos módulos auxiliares prontos para utilização, como as bibliotecas subprocess e distutils. Estas disponibilizam o acesso à abertura e controle de outros programas, como o emulador FCEUX.

Para controle da comunicação foi utilizado o módulo os que possui a função mkfifo, utilizada para criação de um pipe. Para leitura e escrita dos pipes, foram utilizadas funções próprias do Python de manipulação de arquivos, como open para abrir, write para escrita e read para leitura.

\subsubsection{NEAT- Python}

NEAT-Python é uma biblioteca escrita em Python para facilitar a utilização do algoritmo NEAT. Esta biblioteca foi utilizada neste trabalho para realizar o treinamento da rede neural e a avaliar o seu desempenho. Para efetuar um treinamento mínimo, é necessário criar um arquivo de configuração da rede, onde são preenchidos, entre outras coisas, o número de entradas da rede, a quantidade de saídas, a população e função de cálculo de ativação. Além disso, é necessário construir uma função para treinamento da rede e cálculo de fitness.

Esta biblioteca também possui funções de controle de crescimento da rede neural, aplicando o conceito de stagnation. Através de parâmetros na configuração é possível definir quanto tempo um "espécie" ficam na rede, sendo removidas se ficarem mais gerações que o número indicado.

\subsection{Sistemática experimental}

Para realizar um treinamento de uma rede neural utilizando o pacote NEAT-Python foram definidos os parâmetros mostrados no Quadro 4, configurados no arquivo de configuração da rede.

Quadro 4: Configurações utilizadas neste trabalho para a biblioteca NEATPython.

\begin{tabular}{|l|l|l|}
\hline $\begin{array}{l}\text { Campo da } \\
\text { configuração }\end{array}$ & Valor & Descrição \\
\hline fitness_criterion & Max & Critério para obtenção do fitness \\
\hline fitness_threshold & 10000 & $\begin{array}{l}\text { Limite do fitness. Ao alcançar o sistema chama a } \\
\text { função found_solution. }\end{array}$ \\
\hline pop_size & $\begin{array}{l}5,20,50, \\
100\end{array}$ & Foram utilizados quatro valores de população. \\
\hline
\end{tabular}




\begin{tabular}{|l|l|l|}
\hline $\begin{array}{l}\text { Campo da } \\
\text { configuração }\end{array}$ & Valor & Descrição \\
\hline num_inputs & 43 & $\begin{array}{l}\text { Número de entradas da rede neural. Foram } \\
\text { utilizadas os ID, posições x e y da nave e dos } \\
\text { inimigos e um cálculo de distância. Além disso, o } \\
\text { quadro atual também é enviado para a rede. }\end{array}$ \\
\hline num_outputs & 5 & $\begin{array}{l}\text { Número de saídas da rede neural. As saídas foram } \\
\text { os quatro botões de movimentação (esquerda, } \\
\text { direita, cima, baixo) e disparo. }\end{array}$ \\
\hline
\end{tabular}

Fonte: Elaborado pelos autores (2019).

Esses parâmetros foram definidos depois de alguns testes de treinamento para ver quais eram necessários. $O$ parâmetro do tamanho da população foi definido desta forma para haver uma comparação na evolução deste número. Para realizar um treinamento completo, são necessários diversos passos, listados no Quadro 5.

Quadro 5: Lista de passos necessários para completa simulação e treinamento da rede neural.

\begin{tabular}{|l|l|}
\hline Passos & Explicação \\
\hline $\begin{array}{l}\text { Abrir o emulador FCEUX } \\
\text { através do módulo subprocces } \\
\text { na linguagem Python. }\end{array}$ & $\begin{array}{l}\text { Este é o primeiro passo e necessário para que a } \\
\text { simulação comece. Ele abre o emulador FCEUX e } \\
\text { designa as configurações para abrir também o código } \\
\text { Lua. }\end{array}$ \\
\hline $\begin{array}{l}\text { Realizar a criação dos } \\
\text { pipes e então começar a } \\
\text { comunicação e simulação do } \\
\text { jogo. }\end{array}$ & $\begin{array}{l}\text { Através dos pipes é que o jogo começa a simular, } \\
\text { realizando os primeiros comandos, passando o meno } \\
\text { do jogo. }\end{array}$ \\
\hline $\begin{array}{l}\text { Realização do treinamento } \\
\text { da rede neural. }\end{array}$ & $\begin{array}{l}\text { Agora que o jogo está sendo simulado e a comunicação } \\
\text { já ocorre, o sistema começa a treinar a rede neural com } \\
\text { os dados que são retornados. }\end{array}$ \\
\hline Reinicialização dos sistemas. & $\begin{array}{l}\text { Todos os momentos que a nave é destruída pelos } \\
\text { inimigos, o sistema é iniciado novamente. Isto ocorre } \\
\text { no script Lua usando o comando do emulador "emu. } \\
\text { softreset()". }\end{array}$ \\
\hline
\end{tabular}

Fonte: Elaborado pelos autores (2019).

\subsection{Cálculo do fitness}

Diversas funções de cálculo foram implementadas e nenhuma funcionou perfeitamente: este foi o maior desafio do experimento. A função que obteve 
melhor resultado, e então foi utilizada nos testes, foi a que utilizava o maior quadro (frame, em inglês) que a nave conseguiu atingir durante uma jogada. Além disso, para cada quadro era verificado quantos inimigos estavam com distância menor que 10 unidades, se removendo 0,1 para cada nave próxima e 10 para qualquer disparo próximo. A função de fitness ficou então desta forma: fitness $=$ maiorframe $-\left(\sum\right.$ inimigospróximos $* 0,1+\sum$ disparosnimigospróximos $\left.* 10\right)$

As naves e os disparos inimigos têm pesos diferentes, pois contra as naves pode ocorrer deste inimigo ser eliminado, não ocorrendo o mesmo para os disparos, uma vez que estes não podem ser destruídos, fazendo com que o personagem precise necessariamente se desviar.

Um episódio pode ser considerado uma tentativa de uma população de tentar suceder. Para cada tentativa, um indivíduo é selecionado da população e então as entradas e saídas são proporcionadas pela rede. Após falha ou sucesso desse indivíduo é então calculado o seu fitness e então é avaliado a forma de evolução.

\section{ANÁLISE DOS RESULTADOS}

Os resultados obtidos a partir de treinamentos utilizando variações de gerações e populações estão listados no Quadro 6.

Quadro 6: Medidas após a variação de diversos parâmetros de treinamento.

\begin{tabular}{|l|l|l|l|l|l|l|}
\hline Gerações & População & $\begin{array}{c}\text { Tempo } \\
\text { médio } \\
\text { de cinco } \\
\text { tentativas } \\
\text { (min) }\end{array}$ & $\begin{array}{c}\text { Tempo } \\
\text { total } \\
\text { (min) }\end{array}$ & $\begin{array}{c}\text { Fitness } \\
\text { médio } \\
\text { de cinco } \\
\text { tentativas }\end{array}$ & $\begin{array}{c}\text { Fitness } \\
\text { máximo }\end{array}$ & $\begin{array}{c}\text { Quadro } \\
\text { máximo } \\
\text { alcançado }\end{array}$ \\
\hline 5 & 5 & 1 & 3 & 2748 & 2858 & 2317 \\
\hline 5 & 20 & 4 & 19 & 2618 & 2950 & 2432 \\
\hline 5 & 50 & 10 & 48 & 2917 & 3044 & 2433 \\
\hline 5 & 100 & 4 & 22 & 2864 & 3045 & 2410 \\
\hline 25 & 5 & 17 & 83 & 3110 & 3191 & 2436 \\
\hline 25 & 20 & 34 & 169 & 3975 & 5059 & 4834 \\
\hline 25 & 50 & 7 & 36 & 2985 & 3105 & 2433 \\
\hline 25 & 100 & 42 & 211 & 3550 & 4187 & 3411 \\
\hline 50 & 5 & 83 & 417 & 4033 & 5429 & 4831 \\
\hline 50 & 20 & 13 & 63 & 3043 & 3164 & 2435 \\
\hline 50 & 50 & 77 & 383 & 3323 & 3516 & 2704 \\
\hline 50 & 100 & 167 & 848 & 4458 & 6059 & 5327 \\
\hline
\end{tabular}

Elaborado pelos autores (2019). 
Inicialmente observa-se que a evolução segue uma tendência exponencial no tempo para realizar o treinamento da rede neural, tal como apresentado nas Figuras 2 e 3 :

Figura 2: Gráfico demonstrando evolução de tempo com a variação de gerações.

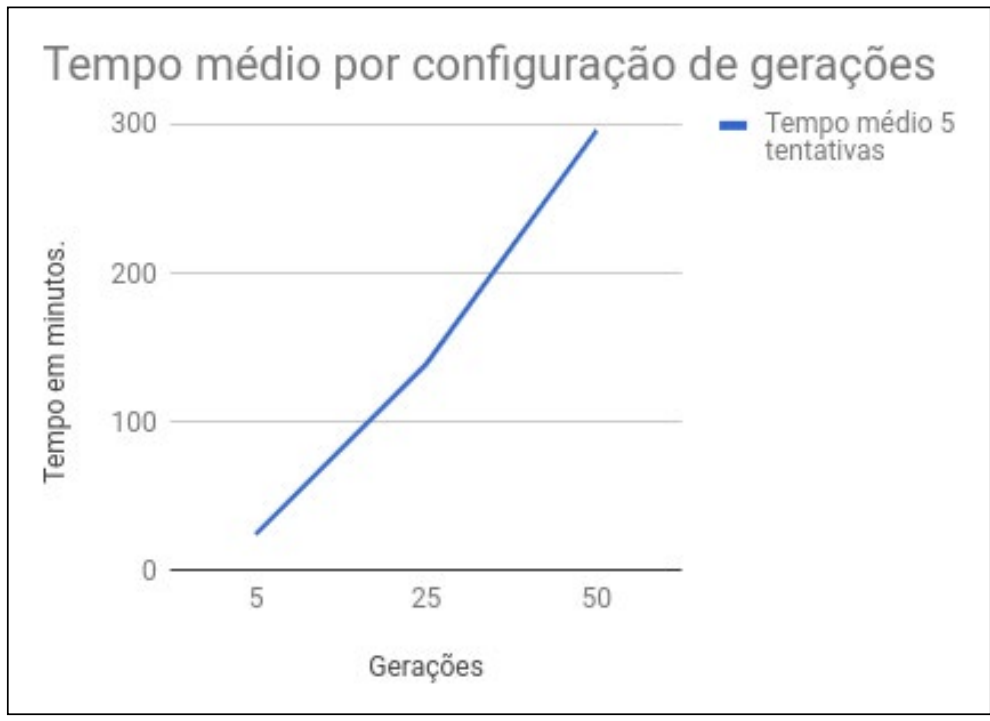

Fonte: Elaborado pelos autores (2019).

Figura 3: Gráfico demonstrando evolução de tempo com a variação de população.

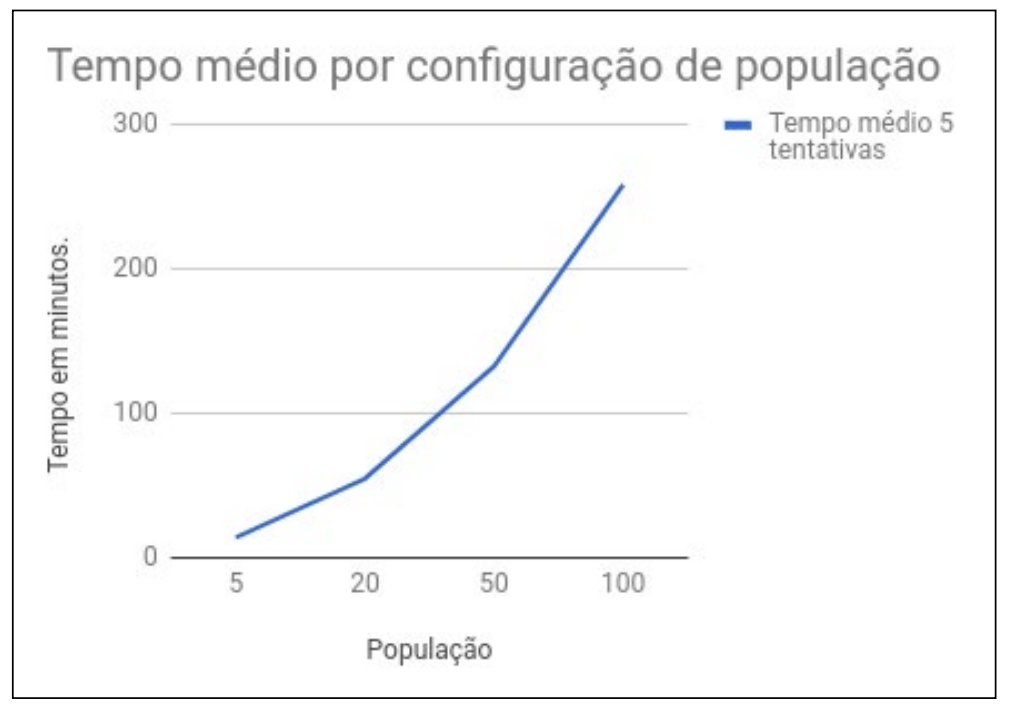

Fonte: Elaborado pelos autores (2019). 
Pode-se perceber uma evolução significativa quando é variado o número de gerações $(5,25$ e 50$)$ e o tamanho da população $(5,20,50$ e 100). A Figura 4 mostram os valores obtidos agrupados por geração, enquanto a Figura 5 mostra os valores agrupados por tamanho da população.

Figura 4: Variação de fitness com diferentes configurações de populações.

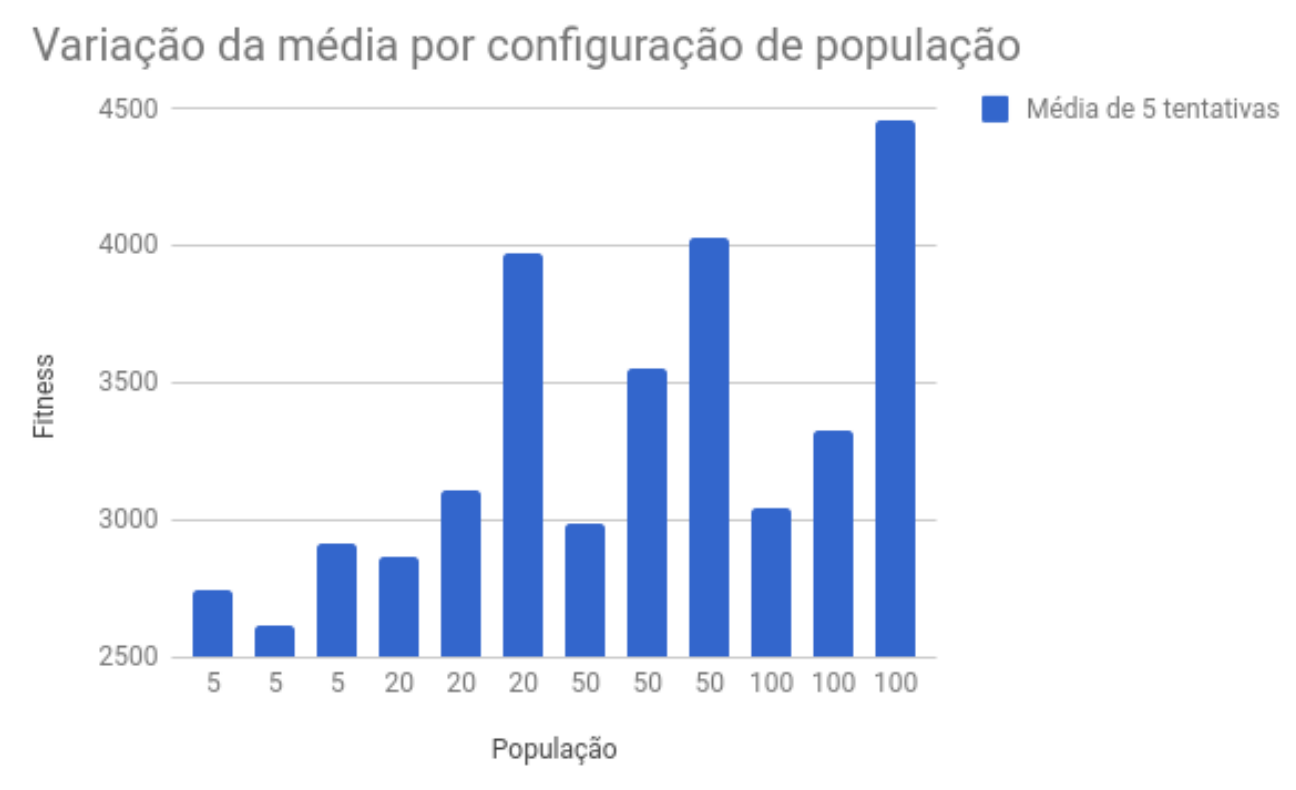

Fonte: Elaborado pelos autores (2019). 
Figura 5: Variação de fitness com diferentes configurações de gerações.

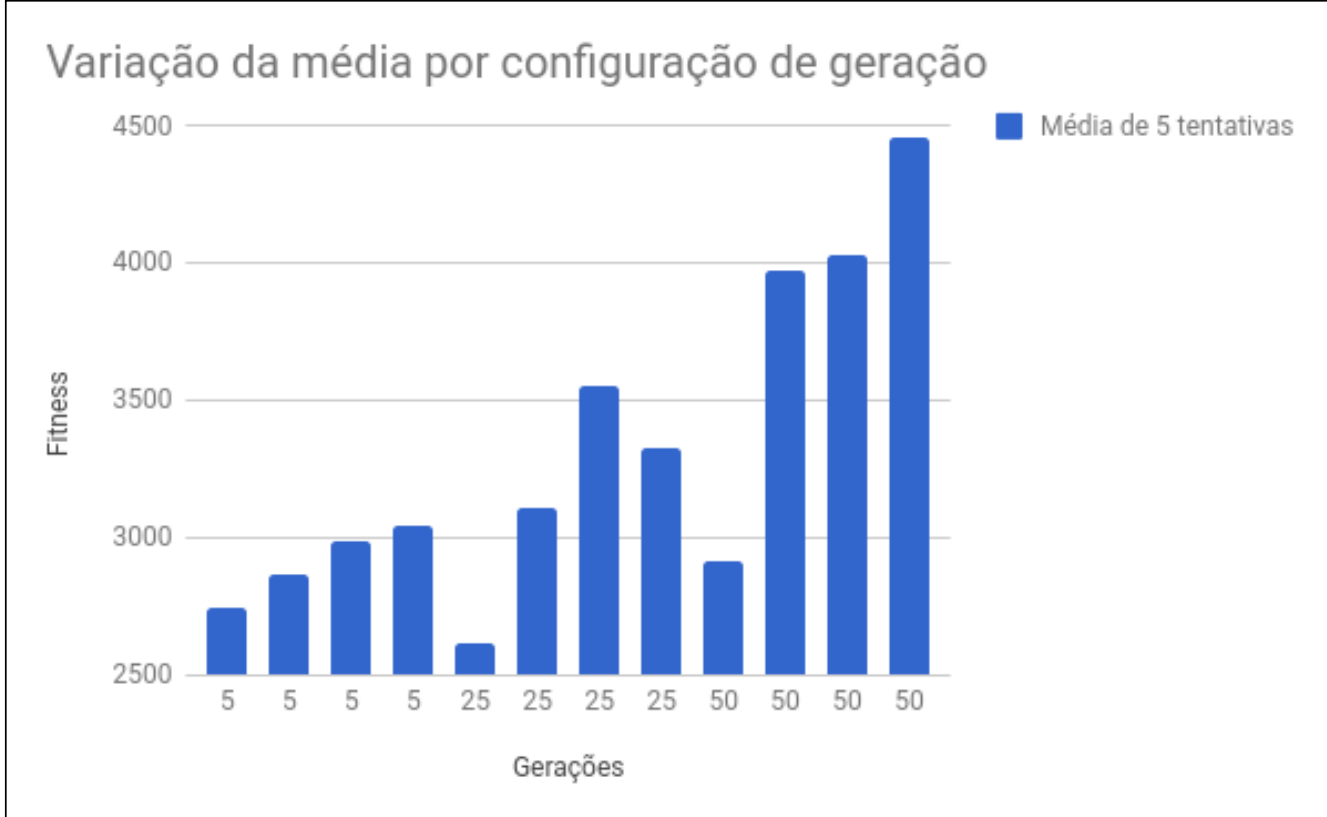

Fonte: Elaborado pelos autores (2019).

Durante os treinamentos foi possível perceber que a rede neural encontrava lugares onde não era possível a nave Vic Viper ser acertada, conseguindo então grandes pontuações sem movimentação. Esses casos garantem um fitness grande pois o maior fator para o fitness é permanecer vivo. As Figuras 6 e 7 ilustram isso ocorrendo. 
Figura 6: Imagem demonstrando a nave parada em uma posição onde não é atingida.

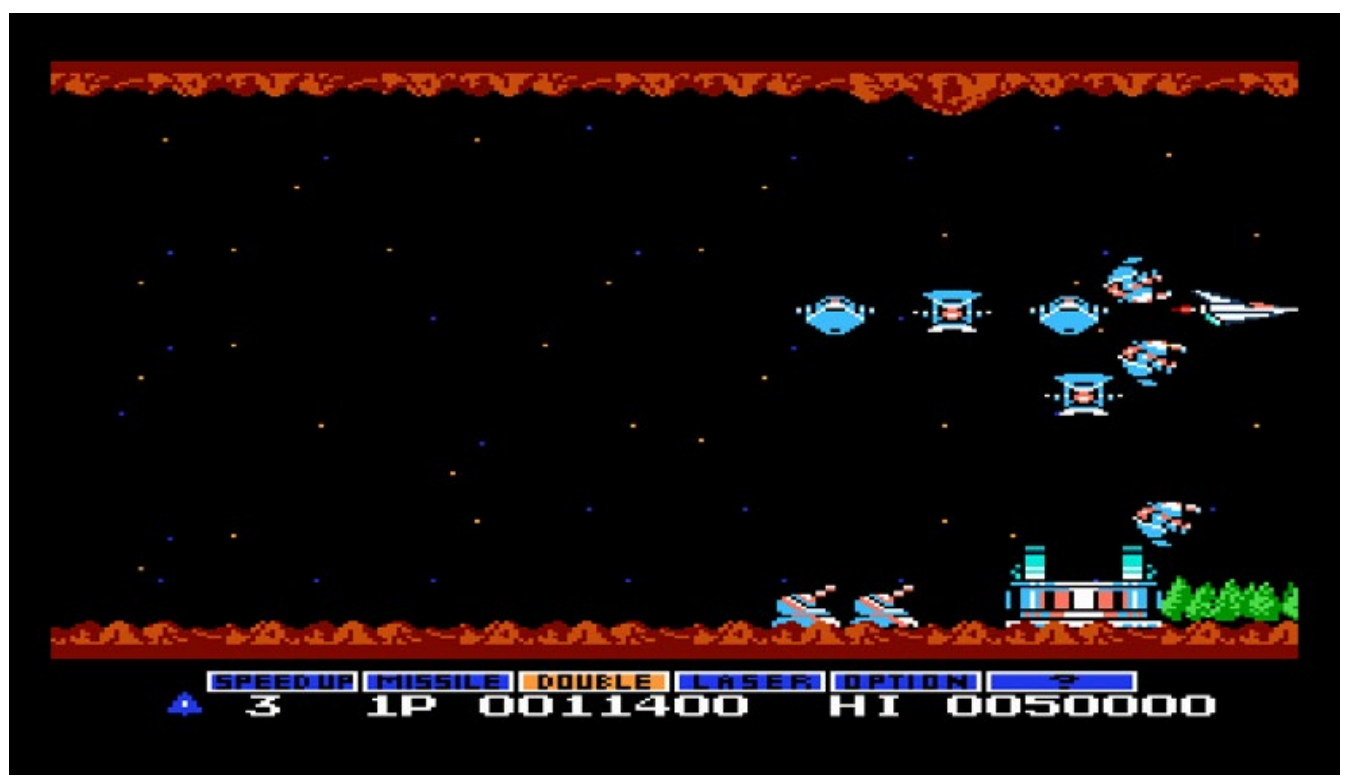

Fonte: Elaborado pelos autores (2019).

Figura 7: Outra imagem demonstrando a nave parada, desta vez quase no final do cenário.

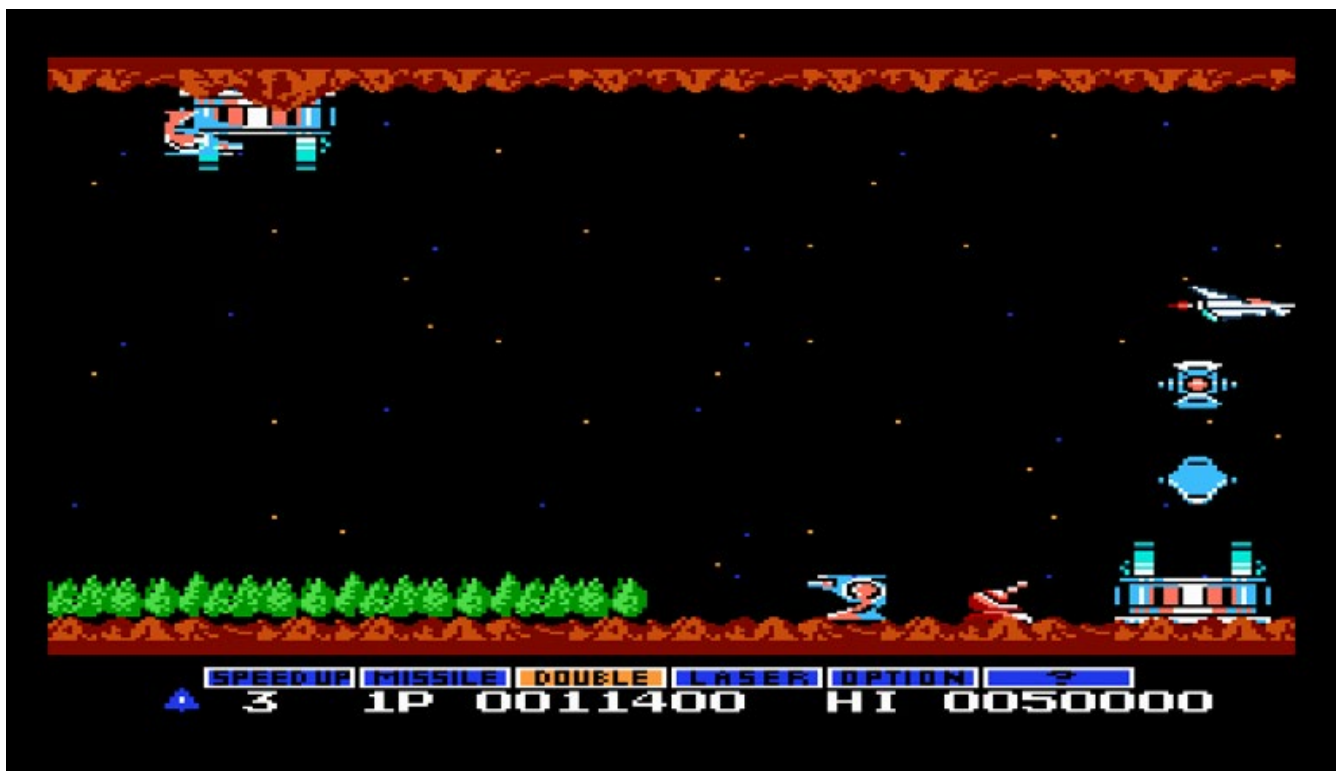

Fonte: Elaborado pelos autores (2019). 


\section{CONCLUSÕES}

Neste trabalho foi realizada a análise do algoritmo de aprendizado NEAT aplicado a um jogo eletrônico do Nintendo Entertainment System (NES), utilizando emulador específico para este console, comunicação entre processos em Lua e rotinas de Aprendizado por Reforço escritas em Python.

A utilização do algoritmo NEAT apresentou-se satisfatória para treinamento de uma rede neural, demonstrando resultados muitos bons para pouco tempo de treinamento e considerando que o jogo Gradius é um jogo onde é necessária movimentação constante e destruição das naves para conseguir sobreviver.

Durante as realizações das simulações foi possível perceber que a evolução ocorria de forma gradual, começando com a nave fazendo nada e se destruindo diversas vezes para os primeiros inimigos para terminar com ela descobrindo posições em que poderia ficar sem ser alvejada. Também foi possível perceber que a nave dava prioridade em alguns momentos para destruição das naves inimigas, desta forma podendo obter mais pontuação e sobrevivendo durante mais tempo.

Uma limitação deste trabalho é que não foi possível terminar a primeira fase do jogo Gradius com a quantidade de testes feitos. Com mais treinamento e ajustes da rede neural, entende-se que é possível concluir a fase e atingir o inimigo chefe ao final.

Outras possibilidades de trabalhos futuros são: a melhoria da função fitness, a utilização de GPUs para aumentar o desempenho do treinamento da rede neural, a exploração de combinações diferentes de populações e gerações, e ainda o teste de configurações diferentes para o pacote NEAT-Python.

\section{REFERÊNCIAS}

BRAGA, Antônio de Pádua; CARVALHO, André Carlos Ponce de Leon Ferreira de; LUDEMIR, Teresa Bernarda. Redes Neurais Artificiais: TEORIA E APLICAÇÕES. $2^{\circ}$ edição. 2011.

HOOJAT, Babak. The AI Resurgence: why now? Disponível em: <https://www. wired.com/insights/2015/03/ai-resurgence-now/>. Acesso em: 25 out. 2017.

KRAMER, O. Genetic Algorithms Essentials. International publishing, 2017.

MCCALL, John. Genetic Algorithms For Modelling And Optimisation. School of Computing, Robert Gordon University. Escócia : United Kingdom. 2005.

RITCHIE, Dennis M.; THOMPSON, Ken. The Unix Time-sharing System. Bell Laboratories, 1974. 
RUSSEL, Stuart J; NORVIG, Peter. Artificial Intelligence: A Modern Approach. Third Edition. Upper Saddle River, New Jersey, 2010.

SAS. Machine Learning. Oque é e qual a sua importância. 2018. Disponível em <https://www.sas.com/pt_br/insights/analytics/machine-learning.html > Acessado em junho de 2018.

SMOLA, Alex; VISHWANATHAN S.V.N. introduction to machine learning. Departments of Statistics and Computer Science, Purdue University, 2008.

STANLEY, Kenneth O.; MIIKKULAINEN, Risto. Evolving Neural Netoworks Through Augmenting Topologies. Department of Computer Science, University of Texas, Austin. 2002.

SUTTON, Richard S.; BARTO, Andrew G. Reinforcement Learning: An Introduction. Second Edition. Cambridge, Massachusetts. 2016. 